\title{
Modulation of amino acid transport in preimplantation mouse embryos by low concentrations of non-ionic and zwitterionic detergents*
}

\author{
C. L. Keefer and R. J. Tasca
}

School of Life and Health Sciences, University of Delaware, Newark, Delaware 19711, U.S.A.

\begin{abstract}
Summary. In 4-cell embryos (but not in blastocysts), Triton X-100, a non-ionic detergent, stimulated leucine, phenylalanine, methionine and glutamic acid transport from 1-6-to $3 \cdot 2$-fold. All of these amino acids were transported exclusively by a sodiumindependent mechanism. Triton X-100, however, did not stimulate the transport of other amino acids tested in 4-cell embryos. Furthermore, phenylalanine transport rates were stimulated about 2-fold at the 4-cell stage by all of the non-ionic and zwitterionic detergents tested at concentrations which were approximately one-tenth of the critical micellar concentration for each detergent. These concentrations did not block development, disrupt the cells, or make the cell membranes freely permeable.

At the blastocyst stage, Z312, a zwitterionic detergent, inhibited the transport of phenylalanine and alanine and stimulated the transport of lysine, a pattern previously found to be linked to the sodium-dependent amino acid transport mechanism. We suggest that Z312 may be acting upon some component of sodium-dependent amino acid transport in blastocysts.

The non-ionic and zwitterionic detergents seemed to have a common effect on amino acid transport in 4-cell embryos but elicited varied transport responses from blastocysts. These differential responses to detergents by blastocysts may reflect intrinsic changes in membrane composition and/or organization which occur during the normal course of preimplantation development.
\end{abstract}

\section{Introduction}

The development of nutrient transport systems is an important feature of early mammalian embryogenesis. This development is characterized by increasing rates of amino acid and nucleoside transport and activation of sodium-dependent amino acid transport as early cleavage-staged mouse embryos become morulae and blastocysts (Tasca \& Hillman, 1970; Brinster, 1971; Epstein \& Smith, 1973; Borland \& Tasca, 1974, 1975; Epstein, 1975, review; DiZio \& Tasca, 1977). Maximum transport rates occur at the blastocyst stage as the blastocyst prepares for hatching, growth and implantation and as the trophectodermal tissue and the inner cell mass (presumptive embryo) become distinct groups of cells. In-vitro experiments have shown that certain amino acids are 'essential' for blastocyst hatching, attachment and outgrowth of the post-implantation mouse embryo (Spindle \& Pedersen, 1973). Leucine and methionine are included in this group and their transport in mouse embryos has been studied intensively (Tasca \& Hillman, 1970; Epstein \& Smith, 1973; Borland \& Tasca, 1974, 1975; Holmberg \& Johnson, 1979; Kaye, Schultz, Johnson,

*Reprint requests to Dr R. J. Tasca. 
Pratt \& Church, 1982). There is strong evidence that a carrier-mediated transport system for these amino acids is present in unfertilized mouse eggs, early cleavage-stage embryos and blastocysts (Epstein \& Smith, 1973; Borland \& Tasca, 1974; Holmberg \& Johnson, 1979). In eggs and early cleavage stages, this transport system has features similar to that of the $L$ system defined by Christensen (1975), including $\mathrm{Na}^{+}$-independency, substrate specificities and exchange properties (Borland \& Tasca, 1974; Kaye et al., 1982).

Non-ionic and zwitterionic detergents have been predominantly used to solubilize membranes and isolate specific cell membrane proteins (Helenius \& Simons, 1975). These detergents, available in various carbon chain lengths, are able to bind to hydrophobic regions of membrane proteins, often without destroying the antigenic or other biological function of the membrane proteins. However, lower concentrations of these detergents can be used as valuable probes of cell membrane function in intact cells. At concentrations below those that solubilize membranes, non-ionic and zwitterionic detergents can be incorporated into the intact membrane, increase membrane fluidity, alter cell permeability, and affect in-situ membrane enzyme function (Helenius \& Simons, 1975; Heppel \& Makan, 1977; Gonenne \& Ernst, 1978; Meeks \& Chen, 1979; Juliano \& Gagalong, 1979; Schmidt, Lichtenberg, Jackson \& Litman, 1980). Accordingly, we have extended our earlier amino acid transport studies (DiZio \& Tasca, 1977) by examining the effects of low concentrations of nonionic and zwitterionic detergents on preimplantation mouse embryos.

\section{Materials and Methods}

Collection of embryos. Random-bred albino female mice (8-12 weeks of age) were induced to superovulate by i.p. injection of 5 i.u. PMSG (Gestyl: Organon, West Orange, NJ, U.S.A.), followed 44 h later by i.p. injection of 5 i.u. hCG (Sigma, St Louis, MO, U.S.A.) (Edwards \& Gates, 1959). The mice were then mated with selected males. Pregnant females were identified by vaginal plugs 20-22 h later (Day 1). Two- to 4-cell embryos were collected from the oviducts of pregnant mice on the afternoon of Day 2 and were cultured in vitro in preimplantation culture medium (PCM: Goldstein, Spindle \& Pedersen, 1975) according to Brinster's procedures (Brinster, 1963). Blastocysts were collected from the uteri of pregnant mice on Day 4.

Culture media and radioactive labels. The completely defined culture medium (Ficoll preimplantation culture medium, FPCM) used for these experiments was PCM with bovine serum albumin replaced by $3 \mathrm{~g}$ Ficoll (Pharmacia, Boston, MA, U.S.A.)/l. Tritiated amino acids or uridine (New England Nuclear, Boston, MA, U.S.A.) were used in the following concentrations and specific activity: phenylalanine, $0.18 \mu \mathrm{M}(54.2 \mathrm{Ci} / \mathrm{mmol})$; leucine, $0.17 \mu \mathrm{M}(51.7 \mathrm{Ci} / \mathrm{mmol})$; methionine, $0.20 \mu \mathrm{m}(80.0 \mathrm{Ci} / \mathrm{mmol})$; glutamic acid, $0.23 \mu \mathrm{M}(43.0 \mathrm{Ci} / \mathrm{mmol}) ;$ alanine, $0.62 \mu \mathrm{M}(16 \cdot 1$ $\mathrm{Ci} / \mathrm{mmol}) ; \alpha$-amino-isobutyric acid, $1.0 \mu \mathrm{M}(10 \mathrm{Ci} / \mathrm{mmol}) ;$ glycine, $0.66 \mu \mathrm{M}(15.0 \mathrm{Ci} / \mathrm{mmol})$; threonine, $0.17 \mu \mathrm{M}(3.4 \mathrm{Ci} / \mathrm{mmol}) ;$ lysine, $0.199 \mu_{\mathrm{M}}(73.1 \mathrm{Ci} / \mathrm{mmol})$; uridine, $0.20 \mu \mathrm{M}(30.0$ $\mathrm{Ci} / \mathrm{mmol}$ ). These low concentrations of amino acids or uridine were used to minimize the uptake by diffusion and exchange diffusion (Borland \& Tasca, 1974; Schultz, Kaye, McKay \& Johnson, 1981). Analysis of labelled samples by thin-layer chromatography using $3 \mathrm{~mm}$ cellulose plates (Brinkman, Westbury, NY, U.S.A.) and a butanol :acetic acid : water $(80: 12: 10$ by vol.) solvent system indicated that most of the radioactivity accumulated during $1 \mathrm{~h}$ incubation remained as the labelled amino acid (C. L. Keefer \& R. J. Tasca, unpublished).

Detergent experiments. The non-ionic detergents, Triton X-100 (New England Nuclear), octyl glucoside and decyl glucoside (Calbiochem, San Diego, CA, U.S.A.), and the zwitterionic (sulphobetaine) detergents (Zwittergents, Calbiochem) were made up in $0 \cdot 1 \%$ stock solutions with FPCM.

Samples of 15-20, 4-cell embryos, or 5-15 blastocysts were incubated at $37 \cdot 5^{\circ} \mathrm{C}$ for $1 \mathrm{~h}$ in FPCM containing tritiated amino acid plus the appropriate detergent concentration. After incubation for $1 \mathrm{~h}$, embryos were washed through 4 drops of cold $\left(4^{\circ} \mathrm{C}\right)$ unlabelled FPCM under lightweight 
paraffin oil (Saybolt viscosity 125/135, Fisher, Pittsburgh, PA, U.S.A.) and frozen in $10 \times 75 \mathrm{~mm}$ glass test-tubes. Transport data (mean \pm s.e.m., $n=3-7$ ) were from the soluble fractions of trichloroacetic acid (TCA) precipitation counted by liquid scintillation procedures (DiZio \& Tasca, 1977). Incorporation data (Table 1) were from the acid insoluble fractions of TCA precipitation. The significance of differences between samples was calculated by Student's $t$ test.

To estimate the extent of cell death, embryos were placed in a $0.004 \%$ solution of nigrosin dye in FPCM containing the detergent to be tested. Embryos were incubated as before and observed at 30-min intervals for dye penetration of the cells. Entrance of dye into cells was readily visible as a dense darkening of the cell and was taken as an indication of cell death.

Embryos to be tested for recovery from detergent treatment were incubated in FPCM plus the required detergent concentration as if for a radioactive label, but minus the radioactive amino acid. The detergent-treated embryos were washed in $2 \mathrm{ml}$ warm PCM in a $35 \times 10 \mathrm{~mm}$ tissue culture dish (Falcon, 3001, Oxnard, CA, U.S.A.) and then washed through 4 drops of warm PCM under paraffin oil. The washed embryos were incubated in the last wash drop to determine their ability to develop into morulae and blastocysts. Treated embryos that developed to the blastocyst stage were placed into Modified Eagle's Medium containing 10\% dialysed fetal calf serum (outgrowth medium, Spindle \& Pedersen, 1973) in a $35 \times 10 \mathrm{~mm}$ tissue culture dish to test their ability to form early post-implantation embryos.

\section{Results}

\section{Effects of $T X-100$}

Simultaneous incubation of 4-cell mouse embryos in a tritiated amino acid or $\left[{ }^{3} \mathrm{H}\right]$ uridine for $1 \mathrm{~h}$ with $0.005 \%$ Triton X-100 resulted in a selective pattern of modulation of transport. Transport rates of phenylalanine, leucine, methionine, and glutamic acid were all significantly stimulated by $0.005 \%$ Triton X-100 (Text-fig. 1a), to levels which were from 1.65 (methionine) to 3.2 (phenylalanine) times the control rates for 4-cell embryos. The stimulated rates of transport for phenylalanine $(7.2 \mathrm{fmol} / \mathrm{embryo} / \mathrm{h})$ and leucine $(5 \cdot 2 \mathrm{fmol} / \mathrm{embryo} / \mathrm{h})$ approached the rates of phenylalanine $(9.5 \mathrm{fmol} / \mathrm{embryo} / \mathrm{h})$ and leucine $(5.6 \mathrm{fmol} / \mathrm{embryo} / \mathrm{h})$ transport in control uterine blastocysts (Text-fig. 1). Transport of the other amino acids tested, alanine, glycine, threonine, and lysine, and the non-metabolizable amino acid analogue, $\alpha$-aminoisobutyric acid ( $\alpha$-AIB), was not significantly affected by Triton X-100 treatment. Uridine uptake by 4-cell embryos was significantly decreased to $19 \%$ of the control value in the presence of $0.005 \%$ Triton X-100. The stimulation of leucine and phenylalanine transport by $0.005 \%$ Triton X-100 could also be obtained with a lower concentration $(0.001 \%$, data not shown). These stimulatory concentrations were approximately one-tenth of the critical micellar concentration for Triton X-100 (Text-fig. 1).

The effects of Triton X-100 upon amino acid transport in mouse blastocysts were also determined (Text-fig. 1b). Control blastocysts showed increased rates of transport for amino acids and uridine in comparison with 4-cell mouse embryos (controls, Text-fig. 1). Compared with its effect at the 4-cell stage, $0.005 \%$ Triton X-100 no longer stimulated transport of phenylalanine, leucine, methionine, or glutamic acid. Alanine, $\alpha$-AIB, glycine and threonine remained unaffected. Lysine transport, in contrast to its lack of response to detergent at the 4-cell stage, was significantly stimulated at the blastocyst stage, to 1.9 times the control value. Uridine uptake was significantly decreased to $20 \%$ of the control value. A lower concentration, $0.001 \%$ Triton X-100, also caused no significant modulation of transport rates of phenylalanine, leucine, glutamic acid or alanine (data not shown). At a higher concentration, $0.01 \%$, only very low levels of labelled amino acid were retained by the embryonic cells. (See nigrosin dye experiments below.)

The incorporation of $\left[{ }^{3} \mathrm{H}\right]$ phenylalanine into protein during the 1-h label at the 4-cell stage was inhibited to 25 and $64 \%$ of the control value by $0.005 \%$ and $0.001 \%$ Triton $\mathrm{X}-100$, respectively (Table 1). Leucine incorporation at the 4 -cell stage was inhibited to $23 \%$ of control value by $0.005 \%$ 


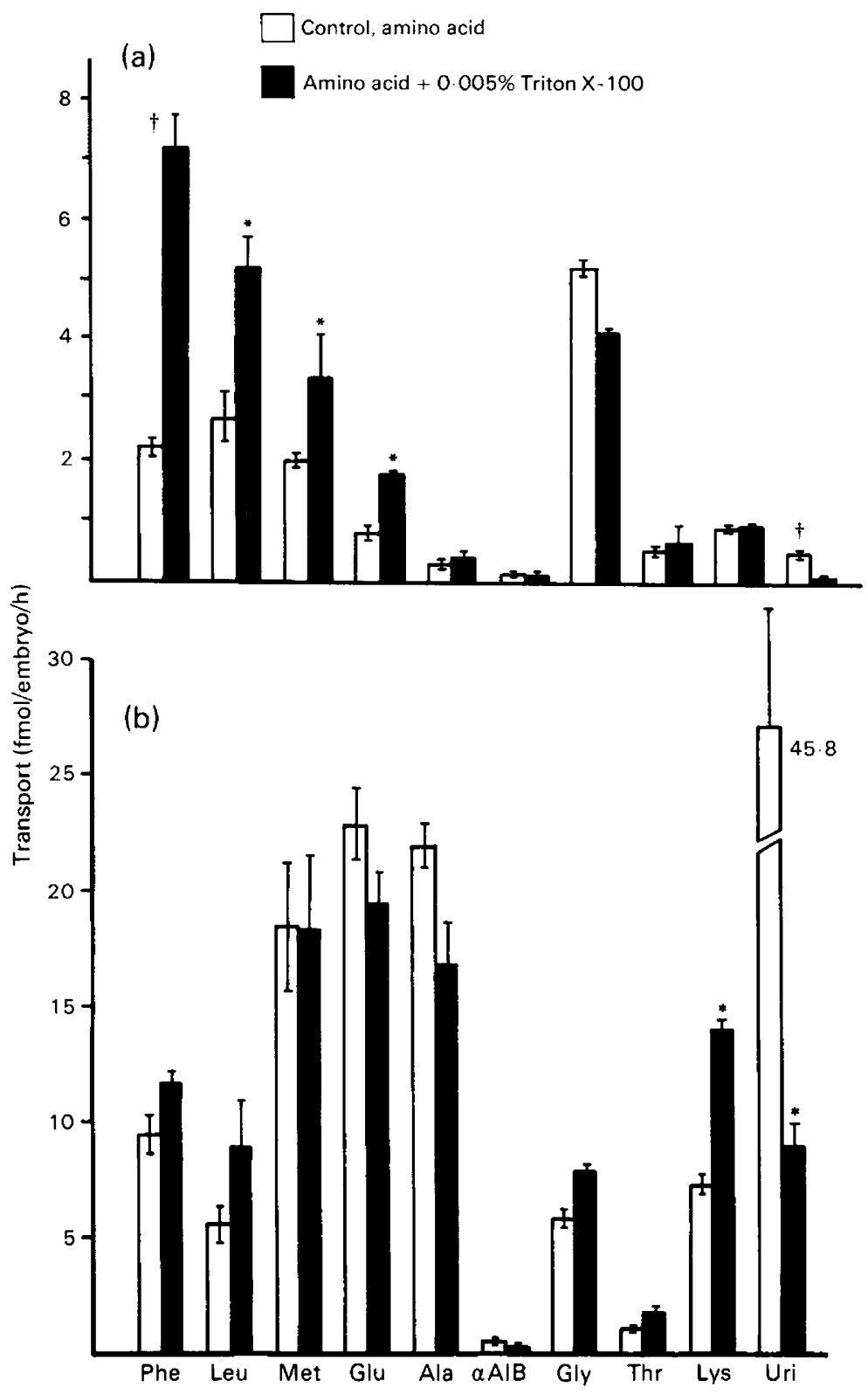

Text-fig. 1. Effect of Triton X-100 upon transport rates in (a) 4-celled mouse embryos and (b) uterine blastocysts. Values are mean \pm s.e.m. for 3-7 observations. ${ }^{*} P<0.01$ compared with control value. $+P<0.001$ compared with control value (data transformed by logarithmic expression before analysis). The CMC for Triton X-100 is $0.24 \mathrm{mM}(0.015 \%)$ (Helenius \& Simons, 1975).

Triton X-100. Incorporation into protein was also inhibited by Triton X-100 at the blastocyst stage, with phenylalanine incorporation decreased to $9 \%$ and leucine incorporation to $2 \%$ of the control levels by $0.005 \%$ Triton X-100 treatment (data not shown). 
Table 1. Transport and incorporation (fmol/embryo/h) of $\left[{ }^{3} \mathrm{H}\right]$ phenylalanine by 4-celled mouse embryos in the presence of various detergents $\dagger$

\begin{tabular}{lll}
\hline & Acid-soluble & Acid-insoluble \\
\hline Control & $2 \cdot 1 \pm 0 \cdot 15$ & $0.36 \pm 0.04$ \\
Triton X-100 $(0.005 \%)$ & $7 \cdot 3 \pm 0 \cdot 6^{*}$ & $0 \cdot 09 \pm 0 \cdot 02^{*}$ \\
Z312 $(0 \cdot 01 \%)$ & $4 \cdot 4 \pm 0 \cdot 3^{*}$ & $0 \cdot 61 \pm 0 \cdot 13$ \\
Decyl glucoside $(0.01 \%)$ & $4.9 \pm 0 \cdot 17^{*}$ & $0 \cdot 15 \pm 0 \cdot 02^{*}$ \\
Octyl glucoside $(0 \cdot 1 \%)$ & $4 \cdot 1 \pm 0 \cdot 4^{*}$ & $0.12 \pm 0^{*}$
\end{tabular}

$\dagger$ Embryos were incubated in $\left[{ }^{3} \mathrm{H}\right]$ phenylalanine $(0 \cdot 18 \mu \mathrm{M})$ for $1 \mathrm{~h}$ in the absence (control) or presence of various detergents, all at one-tenth of their respective CMCs (see Text-fig. legends). Acid-soluble (transport) and acidinsoluble (incorporation) fractions were obtained by TCA precipitation ('Materials and Methods').

$* P<0.01$ compared with control.

\section{Effects of octyl and decyl glucosides}

To determine whether the selective pattern of stimulation of amino acid transport by Triton X100 at the 4-cell stage was due to a specific property of Triton X-100 or to a general detergent property, other non-ionic and zwitterionic detergents were tested. Octyl and decyl glucosides (octyl $\beta$-D-glucopyranoside and decyl $\beta$-D-glucopyranoside) are non-ionic detergents which have been shown to be efficient solubilizers of membrane proteins, allowing retention of the enzymic activity of the membrane protein (Baron \& Thompson, 1975). They are more readily removed from membrane preparations as they have higher critical micellar concentrations (CMC) and a lower affinity for proteins than does Triton X-100 (Baron \& Thompson, 1975). Octyl and decyl glucosides both significantly stimulated phenylalanine transport at the 4-cell stage at concentrations

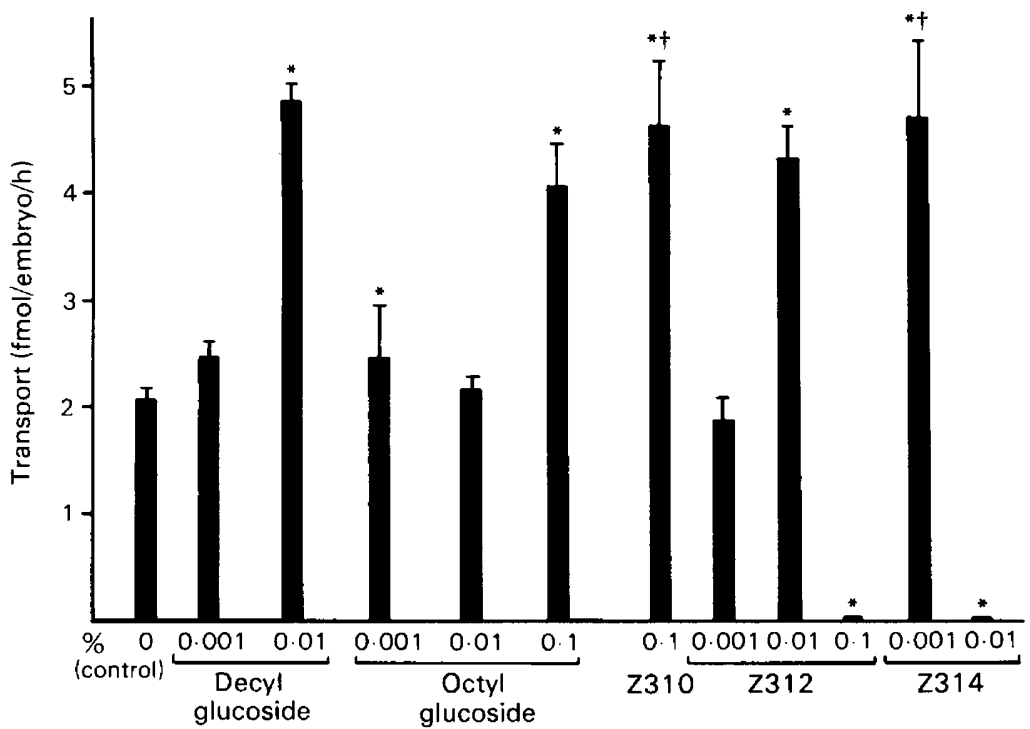

Text-fig. 2. The effect of various concentrations of decyl glucoside, octyl glucoside and Zwittergents on phenylalanine transport rates in 4-celled mouse embryos. Values are mean \pm s.e.m. for 3-7 observations. ${ }^{*} P<0.001$ compared with respective control (Student's $t$ test). †Data transformed by logarithmic expression before analysis. The CMCs are $3 \mathrm{mM}(0 \cdot 1 \%)$ for decyl glucoside, $25 \mathrm{~mm}(0.73 \%)$ for octyl glucoside, $39 \mathrm{mM}(1 \cdot 2 \%)$ for $\mathrm{Z310}, 4 \mathrm{~mm}(0 \cdot 12 \%)$ for Z312, and $0.3 \mathrm{mM}(0.012 \%)$ for Z314 (Helenius \& Simons, 1975). 
approximately one-tenth their CMCs (Text-fig. 2). Furthermore, $\left[{ }^{3} \mathrm{H}\right]$ phenylalanine incorporation into protein was inhibited significantly by octyl and decyl glucoside at these concentrations (Table 1). Lower concentrations did not stimulate phenylalanine transport. A $0.1 \%$ octyl glucoside concentration caused the collapse of blastocysts during treatment for $1 \mathrm{~h} ; 0.01 \%$ octyl glucoside did not have this effect. Phenylalanine transport rates at the blastocyst stage, however, were not significantly altered by $0.1 \%$ or by $0.01 \%$ octyl glucoside (data not shown). Alanine transport rates in blastocysts were also not significantly affected by $0.1 \%$ or $0.01 \%$ octyl glucoside. As found in previous experiments (DiZio \& Tasca, 1977) blastocyst collapse did not seem to interfere with amino acid transport.

\section{Effects of zwitterionic detergents}

Concentrations of the zwitterionic detergents of approximately one-tenth the CMC caused stimulation of phenylalanine transport rates at the 4-cell stage (Text-fig. 2). Z310 (0.1\%), Z312 $(0.01 \%)$, and $\mathrm{Z} 314(0.001 \%)$ stimulated phenylalanine transport rates to approximately the same level, i.e. $2 \cdot 2$ times the control value. Pretreatment with $0 \cdot 1 \%$ Z310 for $1 \mathrm{~h}$ did not significantly affect the subsequent transport of phenylalanine at the 4-cell stage (data not shown). Higher concentrations, near the CMC, or Z312 $(0.1 \%)$ and Z314 $(0.01 \%)$ caused loss of membrane integrity, as determined by nigrosin dye penetration (see below). At these higher detergent concentrations, very low levels of the labelled amino acid were retained, as expected. Alanine transport was not affected by $0.01 \% \mathrm{Z} 312$ at the 4-cell stage (data not shown).

At the blastocyst stage, $0.01 \% \mathrm{Z} 312$ inhibited phenylalanine transport rates $(29 \%$ of control value) and alanine transport rates ( $8 \%$ of control value) (Text-fig. 3). A lower concentration, $0.001 \%$ Z312, also inhibited phenylalanine transport ( $41 \%$ of control, data not shown). However, the lysine transport rate at the blastocyst stage was stimulated by $0.01 \% \mathrm{Z} 312$ (Text-fig. 3 ).

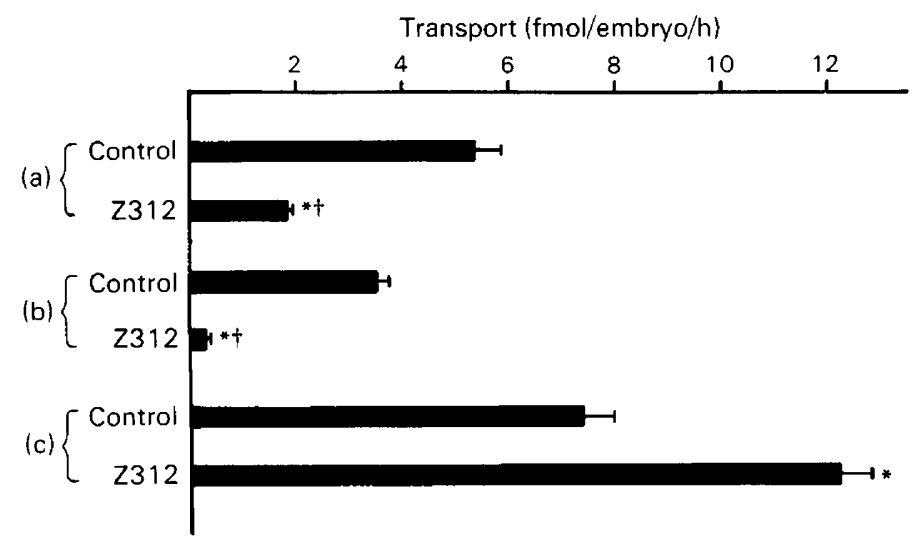

Text-fig. 3. Effect of $0.01 \%$ Z312 upon (a) phenylalanine, (b) alanine and (c) lysine transport rates in blastocyst-stage mouse embryos. Values are mean \pm s.e.m. for 3-7 observations. ${ }^{*} P<0.001$ compared with respective control (Student's $t$ test). †Data transformed by logarithmic expression before analysis.

The effects of phenylalanine, alanine, and lysine transport at the blastocyst stage by Z312 were strikingly similar to the effects on transport by ouabain inhibition of $\mathrm{Na}^{+}-\mathrm{K}^{+}-\mathrm{ATPase}$ activity (DiZio \& Tasca, 1977). Therefore, to determine whether Z312 and ouabain are both acting on $\mathrm{Na}^{+}-\mathrm{K}^{+}-$ATPases, the ability of cytochalasin B-collapsed blastocysts to re-expand, which is dependent on $\mathrm{Na}^{+}-\mathrm{K}^{+}$-ATPase activity, was tested. Cytochalasin B-collapsed blastocysts were able to re-expand in the presence of $0.01 \% \mathrm{Z} 312$ within $90 \mathrm{~min}$ after removal from cytochalasin $\mathrm{B}$. 
The incorporation of $\left[{ }^{3} \mathrm{H}\right]$ phenylalanine into protein during the 1-h label at the 4-cell stage was not affected by $0.01 \% \mathrm{Z} 312$, unlike the inhibition of incorporation caused by Triton X-100 and octyl and decyl glucosides (Table 1). Incorporation into protein was not affected by Z312, even at the blastocyst stage when the transport rate of phenylalanine was inhibited $71 \%$ by $0.01 \% \mathrm{Z} 312$ (data not shown).

\section{Effects of detergents on development and viability}

Treatments of 4-cell embryos for $1 \mathrm{~h}$ with $0.1 \% \mathrm{Z310}, 0.01 \% \mathrm{Z3} 12,0.01 \%$ decyl glucoside, or 0.001 or $0.005 \%$ Triton X-100 (all at about one-tenth of their respective CMCs) allowed development into blastocysts when treated embryos were placed into fresh PCM after careful washing. In outgrowth medium, these blastocysts developed into inner cell masses and trophoblastic cells. Higher concentrations of Triton X-100 (0.01\%) stopped development at the treated stage while even higher concentrations $(0.1 \%)$ caused rapid disintegration of the embryos at the time of treatment. In the presence of these higher concentrations $(0.01$ and $0.1 \%)$, the transport rates were reduced to negligible values (data not shown).

Four-cell embryos excluded nigrosin dye during treatments for $1 \mathrm{~h}$ at the detergent concentrations which stimulated phenylalanine transport, but dye quickly entered at higher detergent concentrations, indicating cell death. Likewise, the usual impermeability of the cell membranes to $\left[{ }^{3} \mathrm{H}\right]$ UTP was not altered by Triton X-100 treatment $(0.001$ or $0.005 \%$, preliminary experiments), further evidence that the stimulatory concentrations do not destroy the integrity of the cell membranes. Thus, the increased or decreased amino acid or uridine transport rates obtained with low concentrations of TX-100 and the other non-ionic and zwitterionic detergents tested represented stimulation of inhibition of specific transport processes, and were not due to alterations in general permeability of cell membranes (Heppel \& Makan, 1977). The low, stimulatory concentrations were below the $\mathrm{CMC}$, and were, in all cases studied here, approximately one-tenth of the CMC for the non-ionic and zwitterionic detergents.

\section{Discussion}

One of the most important results of the present experiments is that the transport of leucine, methionine, phenylalanine, and glutamic acid in 4-cell embryos is significantly increased by the Triton X-100 treatment (Text-fig. 1). At the 4-cell stage, all four of these amino acids are transported by a completely sodium-independent mechanism (Borland \& Tasca, 1974; DiZio, 1978). There is considerable evidence of carrier-mediated transport of leucine and methionine by unfertilized mouse eggs, early cleavage-stage embryos, and blastocysts (Epstein \& Smith, 1973; Borland \& Tasca, 1974; Epstein, 1975; Holmberg \& Johnson, 1979). In eggs and cleavage-stage embryos, this transport system resembles the $L$ system defined by Christensen (1975) in that it is $\mathrm{Na}^{+}$-independent, has similar substrate specificities, and is highly exchangeable (Kaye et al., 1982). Changes in $V_{\max }$ for leucine and methionine transport which occur between the 4-cell and blastocyst stages indicate an increase in number or mobility of carriers (Borland \& Tasca, 1974). Competition for transport in cleavage-stage embryos has been observed between methionine, leucine and phenylalanine but there is no evidence of competition by glycine, alanine, $\alpha$ aminoisobutyric acid, or lysine for this L-like system (Epstein \& Smith, 1973; Borland \& Tasca, 1974; Epstein, 1975; Holmberg \& Johnson, 1979; Kaye et al., 1982). In addition to this selective modulation of the transport of these amino acids by the non-ionic detergent Triton X-100, the other non-ionic and zwitterionic detergents tested are also able to stimulate phenylalanine transport at the 4-cell stage. It is reasonable that stimulation of the transport of amino acids by detergents at the 4-cell stage is due to a change in conformation or conformational mobility of transport 'carriers' caused by a binding of the detergent molecule to the hydrophobic regions of these molecules or 
incorporation into their associated lipids (Helenius \& Simons, 1975). This detergent stimulation may therefore be due to the activation of latent or minimally active cell membrane transport molecules which are already present in unfertilized eggs and persist through the blastocyst stage (Borland \& Tasca, 1974; Holmberg \& Johnson, 1979). Alternatively, the detergents may affect the availability of amino acid pools for increased exchange.

In addition to their modulation of amino acid transport, the non-ionic detergents inhibit amino acid incorporation into protein. This inhibition would, by itself, preclude our interpretation of the stimulation of transport as primarily a membrane effect. However, the zwitterionic detergents, which also stimulate phenylalanine transport at the 4-cell stage, do not inhibit amino acid incorporation. We therefore view the stimulatory effects of the zwitterionic and non-ionic detergents as being primarily a cell surface effect. These results suggest that the zwitterionic detergents would be a better choice for future studies on the regulation of a variety of cell surface functions including transport mechanisms, antigen-antibody reactions, hormone-receptor functions, and cell-cell interactions.

One consistent finding in these experiments is that the effective concentrations of Triton X-100, octyl and decyl glucosides and the zwitterionic detergents are approximately one-tenth of their critical micelle concentrations (CMC). At these concentrations an equilibrium exists between the detergent monomers in solution and those incorporated into the membrane (Helenius \& Simons, 1975; Schmidt et al., 1980). At higher concentrations, close to the CMC, the integrity of the membrane is destroyed, and at concentrations above the CMC the membrane is rapidly solubilized with the formation of detergent-lipid and detergent-protein micelles (Helenius \& Simons, 1975; Gonenne \& Ernst, 1978; Meeks \& Chen, 1979; Schmidt et al., 1980).

The pattern of response to detergents of the normally increased amino acid transport rates at the blastocyst stage is quite different from that at the 4-celled stage. First, the response at the blastocyst stage to a particular detergent is not the same as the 4-cell response to that detergent. Second, the response at the blastocyst stage to the different detergents varies, dependent on the detergent, whereas at the 4-celled stage the response to different detergents is the same. A possible explanation for these changes in response is that membrane organization has altered as a consequence of normal development, thus already activating carrier molecules to their maximum transport rates. An increase in membrane fluidity may occur during normal preimplantation development owing to the increased synthesis of fluidizing components, lysophosphatidylcholine and phosphatidylcholine (Pratt, 1978, 1980). Lysine transport, which was not affected at the 4-cell stage, is significantly stimulated at the blastocyst stage, perhaps because of the appearance of some developmentally controlled, detergent-sensitive component at this stage.

At the blastocyst stage the action of Z312 on transport rates was different from that of the nonionic detergents, causing a drastic decrease in the transport rates of phenylalanine and alanine and an increase for lysine. There is a striking similarity between these results and those obtained in studies of amino acid transport linked to $\mathrm{Na}^{+}-\mathrm{K}^{+}$-ATPase (DiZio \& Tasca, 1974, 1977): the values were 29 and $28 \%$ for phenylalanine, 8 and $6 \%$ for alanine and 165 and $153 \%$ for lysine. It is therefore possible that Z312 was acting upon the $\mathrm{Na}^{+}-\mathrm{K}^{+}-\mathrm{ATPase}$ directly, as proposed for the action of ouabain on blastocyst $\mathrm{Na}^{+}-\mathrm{K}^{+}$-ATPase (DiZio \& Tasca, 1977). However, re-expansion of cytochalasin B-collapsed blastocysts, which is inhibited by ouabain, can occur in Z312, indicating that Z312 is not directly acting on $\mathrm{Na}^{+}-\mathrm{K}^{+}$-ATPases, but on some other component of sodiumdependent transport such as the transport carrier itself or a sodium-binding link to the carrier. This sodium-binding component could be newly inserted or activated at the morula-blastocyst stage, coincident with increasing amounts of sodium-dependent transport (Borland \& Tasca, 1974; DiZio \& Tasca, 1977). The binding of sodium to this component would enhance the binding of the amino acid to the sodium : carrier complex and its subsequent transport (Borland \& Tasca, 1975). It is reasonable to suggest that $\mathrm{Z} 312$ may be interfering with this sodium : carrier complex since Z312 inhibits amino acid transport only at the blastocyst stage when this complex is active and not at the 4-cell stage when transport of phenylalanine and alanine is largely sodium-independent. More 
detailed kinetic studies are needed in order to resolve the mechanism by which detergents affect cell surface functions. However, the present report demonstrates the usefulness of low concentrations of non-ionic and zwitterionic detergents as refined probes of the development of cell membrane function in intact cells and embryos.

This work was supported by National Institutes of Health Research Grant HD-08557, Human Genetics-UNIDEL and Cell Biology-UNIDEL from the University of Delaware, American Cancer Society Grant (No. IN-139), and National Science Foundation Research Grant PCM 8010940 .

\section{References}

Baron, C. \& Thompson, T.E. (1975) Solubilization of bacterial membrane proteins using alkyl glucosides and dioctanoyl phosphatidylcholine. Biochim. Biophys. Acta 382, 276-285.

Borland, R.M. \& Tasca, R.J. (1974) Activation of a $\mathrm{Na}^{+}$dependent amino acid transport system in preimplantation mouse embryos. Devl Biol. 36, 169182.

Borland, R.M. \& Tasca, R.J. (1975) $\mathrm{Na}^{+}$-dependent amino acid transport in preimplantation mouse embryos. II. Metabolic inhibitors and nature of cation requirement. Devl Biol. 46, 192-201.

Brinster, R.L. (1963) A method for in vitro cultivation of mouse ova from two-cell to blastocyst. Expl Cell Res. 32, 205-208.

Brinster, R.L. (1971) Uptake and incorporation of amino acids by the preimplantation mouse embryo. $J$. Reprod. Fert. 27, 329-338.

Christensen, H.N. (1975) Biological Transport, 2nd edn. W. A. Benjamin Company, New York.

DiZio, S.M. (1978) Amino acid transport, development of cell membrane function, and growth control in early mouse embryogenesis. Ph.D. thesis, University of Delaware.

DiZio, S.M. \& Tasca, R.J. (1974) Ion-dependent, ouabain-sensitive re-expansion of mouse blastocyst collapsed with cytochalasin B. J. Cell Biol. 63, 85a, Abstr.

DiZio, S.M. \& Tasca, R.J. (1977) Sodium-dependent amino acid transport in preimplantation mouse embryos. III. $\mathrm{Na}^{+}-\mathrm{K}^{+}$-ATPase-linked mechanism in blastocysts. Devl Biol. 59, 198-205.

Edwards, R.G. \& Gates, A.H. (1959) Timing of the stages of the maturation divisions, ovulation, fertilization, and the first cleavage of eggs of adult mice treated with gonadotrophin. J. Endocr. 18, 292-304.

Epstein, C.J. (1975) Gene expression and macromolecular synthesis during preimplantation embryonic development. Biol. Reprod. 12, 82-105.

Epstein, C.J. \& Smith, S.A. (1973) Amino acid uptake and protein synthesis in preimplantation mouse embryos. Devl Biol. 33, 171-184.

Goldstein, L.S., Spindle, A.I. \& Pedersen, R.A. (1975) Xray sensitivity of preimplantation mouse embryos in vitro. Radiat. Res. 62, 276-287.
Gonenne, A. \& Ernst, R. (1978) Solubilization of membrane proteins by sulfobetaines, novel zwitterionic surfactants. Analyt. Biochem. 87, 28-38.

Helenius, A. \& Simons, K. (1975) Solubilization of membranes by detergents. Biochim. Biophys. Acta $415,28-79$

Heppel, L.A. \& Makan, N. (1977) Methods for rapidly altering the permeability of mammalian cells. $J$. supramol. Struct. 6, 399-409.

Holmberg, S.R.M. \& Johnson, M.H. (1979) Amino acid transport in the unfertilized and fertilized mouse egg J. Reprod. Fert. 56, 223-231.

Juliano, R.L. \& Gagalong, E. (1979) The effect of membrane-fluidizing agents on the adhesion of $\mathrm{CHO}$ cells. J. cell. Physiol. 98, 483-490.

Kaye, P.L., Schultz, G.A., Johnson, M.H., Pratt, H.P.M. \& Church, R.B. (1982) Amino acid transport and exchange in preimplantation mouse embryos. $J$. Reprod. Fert. 65, 367-380.

Meeks, R.G. \& Chen, R.F. (1979) The effect of membrane detergent and retinoic acid on membrane microviscosity. Fedn Proc. Fedn Am. Socs. exp. Biol. 38, 540, Abstr.

Pratt, H.P.M. (1978) Lipids and transitions in embryos In Development in Mammals, Vol. 3, pp. 83-129. Ed. M. H. Johnson. North-Holland, Amsterdam.

Pratt, H.P.M. (1980) Phospholipid synthesis in the preimplantation mouse embryo. J. Reprod. Fert. 58, 237-248.

Schmidt, C.F., Lichtenberg, D., Jackson, M. \& Litman, B.J. (1980) Solubilization of phosphatidylcholine by the nonionic detergent octyl glucoside. Fedn Proc. Fedn Am. Socs. exp. Biol. 39, 1183, Abstr.

Schultz, G.A., Kaye, P.L., McKay, D.J. \& Johnson, M.H. (1981) Endogenous amino acid pool sizes in mouse eggs and preimplantation embryos. J. Reprod. Fert. 61, 387-393.

Spindle, A.I. \& Pedersen, R.A. (1973) Hatching, attachment and outgrowth of mouse blastocysts in vitro: fixed nitrogen requirements. J. exp. Zool. 186, 305318.

Tasca, R.J. \& Hillman, N. (1970) Effects of actinomycin $\mathrm{D}$ and cycloheximide on RNA and protein synthesis in cleavage stage mouse embryos. Nature, Lond. 225, $1022-1025$. 